\title{
Uma visão tranquila e científica do novo Acordo Ortográfico
}

\author{
EVANILDO BECHARA I
}

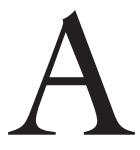

NTES DO último equivocado decreto do governo, que prorrogou o prazo para total implementação do novo sistema ortográfico, o dia $1^{\circ}$ de janeiro de 2013 marcaria o início de sua plena obrigatoriedade. Pode-se dizer que muito antes desse prazo o Acordo já se achava completamente adotado entre nós, graças ao apoio decisivo da maior parte da imprensa escrita e televisiva nacional, das autoridades de ensino do país, dos editores e do magistério de todos os graus, ressalvadas poucas vozes de resistência de pequeno grupo de especialistas, de escritores, de educadores e de jornalistas contrários a mudanças de hábitos ortográficos.

Muitas das vozes de resistência apresentaram e ainda apresentam razões destituídas de qualquer fundamentação real. A primeira delas, compartilhada por vozes fora do país, argumentava que o Acordo de 1990 escondia o propósito de neocolonização por parte do Brasil, porque as Bases ortográficas atendiam mais aos hábitos vigentes entre o nosso país do que aos hábitos vigentes entre portugueses e africanos. Pondo de lado o argumento de que o texto foi assinado sem restrição por representantes de sete nações soberanas, por mais superficial que seja a leitura das Bases, percebe-se que o Acordo mais se aproxima das normas estabelecidas pelo sistema de 1945, corrente entre portugueses e africanos, do que pelo sistema de 1943, oficial somente no Brasil.

Outra argumentação infundada apegava-se ao fato de o Brasil, pela Academia Brasileira de Letras, ter publicado a quinta edição do seu Vocabulário Ortográfico (VOLP) antes de as nações envolvidas, signatárias do texto oficial, terem publicado o vocabulário ortográfico comum de que fala o art. $2^{\mathrm{O}}$ do supracitado texto. Deve-se o argumento mais a confundir as partes e menos a uma leitura inadvertida, porque o art. $2^{\circ}$ não trata do léxico comum, mas sim do léxico das terminologias técnicas e científicas, antigo desejo de acadêmicos lusitanos com vistas à unificação da nomenclatura técnica que corre diversificada entre o domínio linguístico das nações de língua oficial portuguesa. Leiamos o art. $2^{\mathrm{o}} \mathrm{e}$ tiremos nossas conclusões:

Art. $2^{\circ}$. Os Estados signatários tomarão, através das instituições e órgãos competentes, as providências necessárias com vista à elaboração, até $1^{\mathrm{O}} \mathrm{de}$ janeiro de 1993, de um vocabulário ortográfico comum da língua portu- 
guesa, tão completo quanto desejável e tão normalizador quanto possível, no que se refere às terminologias científicas e técnicas.

A restrição final traduz inequivocamente a intenção dos signatários, não dando nenhuma margem de discussão, nesse particular, à pretendida leitura dos adversários da implementação do Acordo. Na oportunidade, cabe lembrar que a preocupação terminológica já estava esboçada no texto que orientou a reforma ortográfica portuguesa de 1945. A normalização da terminologia técnica e científica é tarefa gigantesca e difícil, prenunciada na cautela da redação do art.

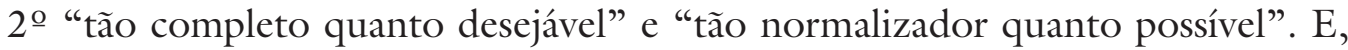
de fato, evidenciou-se a magnanimidade da tarefa, que levou os signatários a desistir do prazo inicialmente proposto em 1990, para concluir a obra: "até 1 o de janeiro de 1993".

Um terceiro subterfúgio alegado pelos inimigos da implementação do Acordo elaborado pela ABL no seu VOLP é que esse se afastava do texto oficial de 1990, e ditava normas próprias, inexistentes nas Bases. O que não observaram os críticos do VOLP foi que o texto de 1990, além de algumas outras novidades, só trazia à discussão para acordo de unificação os pontos em que divergiam entre si as normas dos sistemas de 1943 (brasileiro) e de 1945 (português). O que nesses sistemas era comum não vinha à baila para discussão por motivos óbvios, porque já estavam unificados. Basta recorrer a seus pontos comuns nos dois sistemas para perceber e justificar a sua ausência no texto oficial de 1990, mas em plena vigência, e já observados esses pontos nos vocabulários e dicionários, como foi, por exemplo, o caso do prefixo re: - seguido de palavra começada por $e:-$ reedição, reeleger etc.

Às vezes, trata-se de um evidente engano do texto de 1990, que, repetindo uma lição do texto de 1945, contraria nova lição assumida no texto de 1990; é o caso do debatido prefixo co - em co-herdeiro, quando o texto de 1990 propõe "em geral” a aglutinação desse prefixo (Base XVI, 1ํㅗ b) e obs.). Numa proposta de unificação, firmemente defendida no texto de 1990, não há razão para se usar aglutinado coabitar ao lado de co-berdeiro hifenado. Vale aqui lembrar que o Vocabulário Ortográfico e Remissivo da Lingua Portuguesa que o notável ortógrafo lusitano Gonçalves Viana, editado em 1912, preparou para exemplificar a reforma de 1911, só registra coerdar - coerdeiro. A lição posterior, talvez devida a Rebelo Gonçalves, de atribuir ao prefixo co - o sentido de "a par" para justificar a não aglutinação de palavras como co-berdar, co-berdeiro e co-autor ${ }_{2}$ opondo-se a grafias como coabitar, coonestar e coeducação, ofereceu grande dificuldade de aceitação pacífica, quando ao referido prefixo se atribui o sentido geral da copresença, isto é, onde houver $a$ haverá necessariamente $b$.

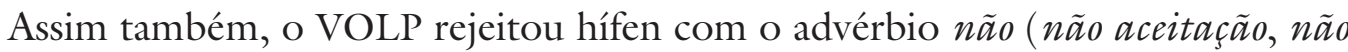
legal), porque até hoje nenhum sistema ortográfico oficial tratou desse caso em língua portuguesa, prática não generalizada, mas hoje corrente por pura influência do francês ou do inglês. 
Prosseguindo o capítulo das críticas infundadas, cabe lembrar aquela que acusa o Acordo de 1990 como ineficiente no seu propósito de unificação ao admitir duplas como, bebêe (Br.) / bebé (Port.), de fato (Br.) / de facto (Port.). Quem assim procede labora em equívoco, por não alcançar o objeto da ortografia; ela se limita à grafia, à vestimenta gráfica da palavra, e não interfere nos fatos de língua, como nos exemplos citados. Bebê e bebé, de fato e de facto são fatos de língua, porque se trata de realidades linguísticas diferentes. Os portugueses empregam duas palavras diferentes, que os dicionários registram em verbetes distintos: fato (= roupa) e de facto (= com efeito). São "variantes" fonéticas. Escrever Egito (Br.) e Egipto (Port.) são apenas variantes gráficas, e não linguísticas, porque se pronunciam igualmente. Nesse caso, o Acordo de 1990 recomenda o não uso da consoante inarticulada, ou muda, Egito em todos os domínios da língua portuguesa escrita. Este, aliás, é o hábito de grafia mais importante de que portugueses e africanos terão de abrir mão, para alívio das crianças que começam a entrar no maravilhoso mundo da língua escrita.

No caso de bebê e bebé, temos duas variantes de língua, e não simplesmente de ortografia, como aconteceu com Egito e Egipto. Bebê e bebé são duas pronúncias de uma mesma palavra, dupla que a ortografia tem de registrar diferentemente, como faz com accessivel e acessivel. Se bebé, proferido com $e$ aberto, é comum em Portugal, também ocorre, por exemplo, em algumas regiões nordestinas brasileiras.

Como dissemos no início destas linhas, não corresponde à verdade afirmar que o Acordo de 1990 atende mais aos hábitos ortográficos brasileiros vigentes desde 1943; por isso mesmo, o novo sistema já se mostra aqui plenamente implantado e obedecido. Quem fez tal declaração ou não leu o texto, ou quer escamotear a verdade com falsos argumentos.

Os brasileiros têm de abrir mão de vários hábitos ortográficos no domínio da acentuação gráfica. Todas em razão de normas fixadas pelo Acordo de 1945, vigentes em Portugal. Deixaremos de marcar com acento agudo ou circunflexo, conforme o caso, desde que não contrarie princípios fixados anteriormente:

1) as vogais $i$ e $u$ tônicas dos paroxítonos quando precedidas de ditongo decrescente: baiuca, maoista, cauila, feiura, feiudo etc. Feíssimo acentua-se, por ser proparoxítono, e guaiba por ter um ditongo crescente;

2) os ditongos abertos ei e oi dos paroxítonos: assembleia, ideia, heroico, jiboia etc., mas não as oxítonas ( réis, anéis), nem Méier, por terminar em $r$, com obediência à regra geral;

3) o encontro oo: voo, enjoo, perdoo etc.;

4) o encontro ee das formas verbais plurais veem, creem, leem, deem.

A iniciativa de retirar o circunflexo de voo, enjoo etc. veio aliviar o sistema de uma notação desnecessária, porque não há outra maneira de pronunciar tais palavras. Por sua vez, não usar circunflexo nas formas verbais creem, leem etc. 
vem corrigir um excesso desnecessário de acentuação gráfica: não há razão para usar circunflexo nesses plurais, pois tal prática nasceu por falsa analogia de plurais do tipo eles têm, eles vêm, ele detém, eles detêm etc.

Abolimos, em consonância com o sistema de 1945, o acento diferencial obrigatório, exceto em pôde e pôr. Será facultado quando o contexto o exigir, especialmente nas oposições do tipo forma/fôrma, sede/sêde etc.: "O poema é forma e não fôrma"; "O coração do cristão não tem sêde nem é sede de vingança".

Reclama-se que a acentuação gráfica diferencial deveria abranger a forma verbal para do verbo parar, para distingui-la da preposição para, em contextos ambíguos do tipo: “O trânsito para Petrópolis". Tal cedência iria atribuir ao acento agudo (pára) a função diferencial, exclusiva; nesses casos, do acento circunflexo, além de abrir a porta para outros contextos. O leitor terá de apelar nesses casos, como nos outros, para a correta interpretação contextual.

No que toca à morfologia, o Acordo de 1990 veio disciplinar o emprego das vogais e e $i$ antes de sílabas tônicas:

a) escrevem-se com $e$, e não $\operatorname{com} i$, as palavras derivadas terminadas em $e$ ou ditongo de sílaba tônica: galeão (de galé), coreano (de Coreia), daomeano (de Daomé), guineense (de Guiné);

b) escrevem-se com $i$, e não $\operatorname{com} e$, as palavras derivadas mediante os sufixos - iano e iense: açoriano (de Açores), acriano (de Acre), camoniano (de Camões), duriense (de Douro);

c) escrevem-se com as terminações - io e ia (átonos) os substantivos com variações ampliadas de outros substantivos terminados em vogal: hástia (de hasta), réstia (do antigo reste), véstia (de veste); em 1943, usavam-se hástea e véstea, com $e$, mas réstia, com $i$.

Uma decisão muito discutida do Acordo de 1990 para seguir o Acordo de 1945 foi a exclusão do trema.

Sábia a decisão do Acordo de 1990, pois, no seu propósito de simplificação dos hábitos ortográficos para o homem comum, tirou a este a incumbência de decidir os casos de pronúncia obrigatória do $u$ nos grupos gue, gui, que, qui, daqueles casos em que há facultatividade da pronúncia, e ainda daqueles casos em que, a rigor, é errada a pronúncia desse $u$. Isso porque o assunto encerra essas três possibilidades, e, ao exigir do homem comum usar ou não o trema, leva-o a uma decisão nem sempre fácil. Assim é que temos palavras nas quais o $u$ átono desses grupos é sempre proferido: consanguíneo, equestre, sequência, lingueta, linguiça, pinguim, sequela. Outras palavras há em que é facultativa a sua pronúncia: antiguidade, equilátero, equivalência, líquido, liquidação, quíntuplo, bilíngue. Em outras, não devia ser pronunciado, mas aparece com frequência: questão, questionário, questionar, distinguir, extinguir, adquirir, inquérito. Não exigir o emprego do trema tira a quem escreve a obrigação de decidir na escrita qual a melhor solução, que só virá, nas indecisões, com a consulta aos dicionários. 
Difícil sistematização para o emprego do hífen, tarefa jamais cabalmente enfrentada pelas anteriores reformas ortográficas, encontrou no Acordo de 1990 o mais inteligente esforço de normatização, que cumpre ser apoiado para se chegar ao melhor resultado possível na complexa operação mental que efetiva o nascimento de uma composição, isto é, da junção de palavras de que resulte uma nova palavra semanticamente independente, ou de visível aderência de sentido.

A sutileza de que se reveste essa operação mental é o grande fator de perturbação no emprego ou não emprego do hífen nas línguas que optaram pela presença desse sinal gráfico para assinalar o nascimento da nova palavra composta. O movimento para encontrar uma sistematização racional e econômica partiu para estabelecer uma primeira divisão entre compostos constituídos de formas livres e formas presas, que integram, respectivamente, as Bases XV e XVI do Acordo de 1990, sem desrespeitar os desvios de exceção da tradição ortográfica comum aos sistemas luso-africanos de 1945 e brasileiro de 1943, que o tempo e a experiência se esforçarão por minorar ou mesmo desaparecer.

\section{1) Do hífen com formas livres}

A nomenclatura gramatical conceitua por forma livre aquela que funciona sozinha, livremente, no discurso; por exemplo, novo é uma forma livre; já neo, que significa também "novo", é uma forma presa, porque só aparece como componente de uma palavra composta, do tipo de neogramático, neopolitico, neossimbolismo. O Acordo dedica dois capítulos (Bases XV e XVI) ao emprego do hífen; o primeiro $(\mathrm{XV})$, quando entram as formas livres, e o segundo (XVI), quando entram as formas presas, procedimento que, bem-vindo, trouxe racionalização das complicadas regras antigas desse sinal gráfico. O princípio geral da Base XV recomenda que se empregue o hífen nos compostos formados por substantivos, adjetivos, numerais e verbos não ligados ao $2^{\circ}$ termo por elementos de ligação:

alcaide-mor
mesa-redonda
azul-escuro
rega-bofe

seu-vizinho
norte-americano
primeiro-ministro
segunda-feira

quebra-mar porta-retrato guarda-chuva vaga-lume

Alguns compostos que a rigor estariam incluídos nesse princípio geral já têm tradicionalmente fixada sua grafia sem hífen; o Acordo lembra girassol, madressilva, pontapé, mandachuva, paraquedas, paraquedista, aos quais a consulta aos dicionários brasileiros e portugueses nos faz acrescentar: cantochão, catassol, claraboia, madrepérola, montepio, outrossim, passaporte, passatempo, rodapé, salsaparrilha, santelmo, varapan, valhacouto. Em caso de dúvida, recorra-se ao dicionário.

O Acordo esqueceu-se de incluir nesse primeiro princípio os compostos em que o termo inicial é um advérbio: abaixo-assinado (= documento), assim-assim, ave-maria, salve-rainba, já-começa etc. 
Se entre os dois termos aparece elemento de ligação, dispensar-se-á o hífen: tenente-coronel, mas general de brigada. Portanto, água de cheiro, boi de mamão, cabeça de negro (= bomba), mesa de cabeceira, pé de boi (= trabalhador), pé de moleque (= doce ou bolo) etc. O Acordo assinala como exceções: água-de-colônia, arco-da-pelha, cor-de-rosa, mais-que-perfeito, pé-de-meia (= economia).

O $2^{\text {o }}$ caso de emprego do hífen se dá com os nomes de lugares (topônimos) formados com os adjetivos grã, grã o, ou com forma verbal ou com elementos que estejam ligados por artigo: Grã-Bretanha, Grão-Pará; Abre-Campos, Passa-Quatro; Baía de Todos-os-Santos, Entre-os-Rios, Trás-os-Montes.

Os outros topônimos compostos se escrevem separadamente sem hífen, tenham ou não elemento de separação: América do Sul, Mato Grosso, Belo Horizonte, Cabo Verde, Freixo de Espada à Cinta. Fazem exceção Guiné-Bissau, fixado pela tradição, e Timor-Leste, pelo uso oficial no novo país independente.

Note-se que os gentílicos (isto é, que indicam o lugar de nascimento) compostos se escrevem com hífen: belo-horizontino, mato-grossense, mato-grossense-do-sul, juiz-forano etc.

Também se usa o hífen nos compostos com os adjetivos grãa, grão, seguindo o $1^{\circ}$ caso já assinalado, quando não entram em topônimos; grã-cruz, grão-mestre.

Um terceiro caso de emprego do hífen com formas livres é o que diz respeito aos compostos que designam espécies botânicas ou zoológicas, estejam ou não ligadas por preposição ou qualquer outro elemento: abóbora-menina, couve-flor, feijão-perde, bênção-de-deus, erva-do-chá; cobra-capelo, bem-te-pi (= pássaro).

Se o composto homógrafo não se aplica a espécie botânica ou zoológica, não ocorrerá o hífen: bico-de-papagaio (= planta) / bico de papagaio (= saliência óssea); pé-de-cabra (= planta) / pé de cabra (= alavanca).

Um quarto caso de emprego do hífen incluído na Base XV se dá quando o $1^{\circ}$ elemento está representado pelas formas além, aquém, recém, bem e sem:

$\begin{array}{lll}\text { além-Atlântico } & \text { recém-casado } & \text { bem-dito } \\ \text { além-fronteira } & \text { recém-nascido } & \text { bem-vindo } \\ \text { aquém-mar } & \text { bem-aventurado } & \text { sem-cerimônia } \\ \text { aquém-Pirineus } & \text { bem-estar } & \text { sem-vergonha } \\ \text { recém-eleito } & \text { bem-humorado } & \end{array}$

Obs.: Quando bem entra num composto com alteração de significado, não ocorre hifenização: bem-dizer (= dizer bem) / bendizer (= abençoar); bem feito! (interjeição) / benfeito (= benefício).

Também se usará hífen quando o $1^{\circ}$ termo é o advérbio mal, que não se liga ao $2^{\circ}$ por qualquer elemento, e que ainda se inicia por vogal, $h$ ou $l:$ mal-entendido, mal-estar, mal-humorado, mal-limpo.

Assim, não se usa hífen em: malcriado, malditoso, malgrado, malsoante, malvisto, malmequer etc. 
Obs.: Quando mal forma um substantivo composto com o significado de "doença”, entra na regra geral, isto é, com hífen, quando não há elemento de ligação, e sem hífen, em caso contrário: mal-francês (= sífilis), mal-caduco (= epilepsia), mas mal de Alzheimer, mal de gota.

O Acordo esqueceu-se dos substantivos compostos formados com elementos repetidos, com ou sem alternância vocálica ou consonântica, do tipo de blá-blá-blá, reco-reco, lenga-lenga, zum-zum, zás-trás, zigue-zague, pingue-pongue, tico-tico, tique-tique, trouxe-mouxe, xique-xique (= chocalho, diferente de xiquexique "planta" e Xiquexique, topônimo). Tais elementos, quase sempre sons de coisas ou vozes de animais, devem ser hifenados conforme a tradição ortográfica; mas não seus derivados: lengalengar, ronronar, zunzunar, por se ter neles esmaecida sua motivação onomatopeica.

Também não se usa hífen nas palavras reduplicativas da linguagem infantil: babá, bumbum, titio, vovó, pipi, xixi etc.

A Base XV termina com um grande pesadelo para quem precisasse escrever unidades linguísticas integrantes de locuções. O princípio anterior obrigava a pessoa a distinguir semântica e gramaticalmente locuções homógrafas. Tomemos dois exemplos: $\grave{a}$-toa, com hífen, quando significa "sem valor", e vale por locução adjetiva (questão à-toa, sujeito à-toa), e à toa, sem hífen, quando significa "inutilmente", e vale como uma locução adverbial (trabalbou à toa). Outro exemplo é dia-a-dia, com hífen, significando "quotidiano" e valendo por substantivo (meu dia-a-dia é agradável), e dia a dia, sem hífen, quando significa "diariamente" e é uma locução adverbial (a criança cresce dia a dia).

Partindo de que não se escrevem com hífen as locuções pronominais (nós mesmos, quem quer que seja etc.), as verbais (quero ver, tenho de dizer etc.), as prepositivas (perto de, depois de, apesar de etc.), as conjuntivas (logo que, enquanto que etc.), o Acordo, racional e coerentemente, aboliu o hífen em todas as locuções, ainda que possam apresentar diferenças de significado e de valor gramatical:

Substantivas: fim de semana, fim de século, dia a dia (quotidiano), calcanhar de aquiles;

Adjetivas: cor de açafrão, à toa ("sem valor");

Pronominais: cada um, ele próprio, quem quer que seja;

Adverbiais: à toa ("inutilmente"), dia a dia ("diariamente"), tão somente;

Prepositivas: abaixo de, por baixo de;

Conjuntivas: a fim de que, ao passo que;

Interjectivas: bem feito! Aqui d'el-rei!

O Acordo abre exceção para os casos fixados pela tradição ortográfica: água-de-colônia, arco-da-velha, cor-de-rosa, mais-que-perfeito, pé-de-meia, como já vimos antes.

Por outro lado, embora delas não fale o Acordo, devem-se incluir na regra 
das locuções as do tipo deus nos acuda, salve-se quem puder, faz de contas, disse me disse, maria vai com as outras, tomara que caia etc.

Também não serão hifenadas as locuções estrangeiras latinas: ad immortalitatem, ad hoc, data venia, causa mortis, ex libris, habeas corpus etc.

\section{2) Do hífen com formas presas}

\section{A) Nas formas com prefixos}

$1^{\circ}$ Emprega-se o hifen:

quando o $1^{\mathrm{o}}$ elemento termina por vogal igual à que se inicia o $2^{\mathrm{o}}$ elemento:

$\begin{array}{lll}\text { anti-infeccioso } & \text { electro-ótica } & \text { sobre-edificar } \\ \text { anti-inflamatório } & \text { entre-eixo } & \text { sobre-elevar } \\ \text { arqui-inteligente } & \text { infra-axilar } & \text { sobre-estadia } \\ \text { arqui-irmandade } & \text { micro-onda } & \text { sobre-estimar } \\ \text { auto-observação } & \text { neo-ortodoxa } & \text { sobre-exceder } \\ \text { contra-almirante } & \text { semi-interno } & \text { supra-auricular }\end{array}$

Obs.: 1: Incluem-se nesse princípio geral os prefixos terminados por vogal: agro- (= terra), albi-, alfa-, ante-, anti-, Antero-, arqui-, auto-, bi-, beta-, bio-, contra-, electro-, euro-, infero-, infra-, intero-, iso-, macro-, mega-, multi-, poli-, póstero-, pseudo-, súpero-, neuro-, orto- etc.

Obs.: 2: a) Nas formações com os prefixos $\mathrm{co}^{-}$, pro-, pre- e $\mathrm{re}^{-}$, essas aglutinam-se em geral com o segundo elemento, mesmo quando iniciado por $o$ ou $e$ :

$\begin{array}{lll}\text { coabitar } & \text { procônsul } & \text { preexistir } \\ \text { coautor } & \text { proembrião } & \text { reedição } \\ \text { coedição } & \text { proeminente } & \text { reedificar } \\ \text { coerdeiro } & \text { prolepse } & \text { reelaborar } \\ \text { coobrigação } & \text { propor } & \text { reeleição } \\ \text { coocupante } & \text { preeleito } & \text { reeducação } \\ \text { coordenar } & \text { preembrião } & \text { reenovelar } \\ \text { cooperação } & \text { preeminência } & \text { reentrar } \\ \text { cooperar } & \text { preenchido } & \text { reescrita } \\ \text { coeminente } & \text { preesclerose } & \text { irreelegível } \\ \text { coenzima } & \text { preestabelecer } & \end{array}$

b) Quando o $1^{\circ}$ e elemento termina por consoante igual à que inicia o $2^{\circ}$ elemento:

ad-digital

hiper-requintado

inter-resistente

Adendo: sub-base

sub-bibliotecário

super-revista 
Formas como abbevilliano, addisoniano, addisonismo, addisonista se prendem a nomes próprios estrangeiros: Abbeville, Addison.

c) Quando o $1^{\circ}$ elemento termina acentuado graficamente pós-, pré-, pró-:

$\begin{array}{lll}\text { pós-graduação } & \text { pré-história } & \text { pró-europeu } \\ \text { pós-tônico } & \text { pró-africano } & \\ \text { pré-escolar } & \text { pró-ativo } & \end{array}$

Adendo:

Pode haver, em certos usos, alternância entre pre- e pré-; neste último caso, usar-se-á o hífen: preembrião / pré-embrião, preesclerótico / pré-esclerótico.

d) Quando o $1^{\circ}$ elemento termina por $m$ ou $n$ e o $2^{\circ}$ elemento começa por vogal, $h, m, n$ :

$\begin{array}{lll}\text { circum-escolar } & \text { pan-africano } & \text { pan-mágico } \\ \text { circum-hospitalar } & \text { pan-americano } & \text { pan-negritude } \\ \text { circum-murado } & \text { pan-harmônico } & \\ \text { circum-navegação } & \text { pan-hispânico } & \end{array}$

e) Quando o $1^{\circ}$ elemento é um dos prefixos que aludem à anterioridade ou cessação: ex-, sota-, soto-, vice-, vizo-:

$\begin{array}{lll}\text { ex-almirante } & \text { sota-almirante } & \text { soto-almirante } \\ \text { ex-diretor } & \text { sota-capitão } & \text { vice-presidente } \\ \text { ex-hospedeira } & \text { sota-mestre } & \text { vice-reitor } \\ & \text { soto-capitães } & \text { vizo-rei }\end{array}$

Adendo:

Fora dessa significação estão os prefixos soto, sota em sotopor e sotavento

f) Quando o $1^{\circ}$ elemento termina por vogal, $r$ ou $b$ e o $2^{\circ}$ elemento se inicia por $h$ :

$\begin{array}{lll}\text { adeno-hipófise } & \text { arqui-hipérbole } & \text { giga-hertz } \\ \text { ante-histórico } & \text { auto-hipnose } & \text { semi-hemisférico } \\ \text { anti-herói } & \text { extra-hepático } & \text { semi-histórico } \\ \text { anti-hemofilico } & \text { geo-história } & \text { sob-roda }\end{array}$

Obs.: Não se emprega o hífen com os prefixos des-, an- e in- quando o $2^{\circ}$ elemento perde o $h$ inicial: desumano, desumidificar; anistórico, anepático, anidrido; inábil, inumano etc. Reduzido a $a$ - (de an) conserva-se o $b$ inicial e usa-se hífen: a-histórico.

Adendo:

Não se emprega o hífen com a palavra não e quase com função prefixal:

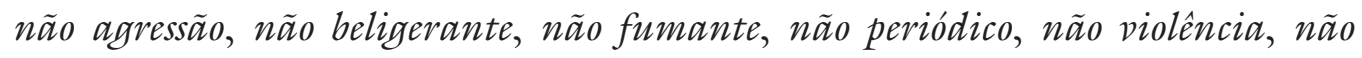
participação; quase solene, quase herói etc. 
g) Quando o $1^{\circ}$ elemento termina por $b\left(a b_{-}, o b_{-}\right.$, sob-, sub- $)$ou $d\left(a d_{-}\right)$e o $2^{\circ}$ elemento começa por $r$ :

$\begin{array}{lll}\text { ad-referendar } & \text { ob-rogar } & \text { sub-réptil } \\ \text { ad-renal } & \text { sob-roda } & \text { sub-rogar } \\ \text { ab-rupto } & \text { sub-reitor } & \end{array}$

Obs.: Adrenalina, adrenalite e afins já são exceções consagradas pelo uso. Abrupto (sem hífen) é hoje mais usado que ab-rupto (com hífen).

$2^{a}$ Não se emprega o bifen:

a) Quando o $1^{\circ}$ elemento termina por vogal e o $2^{\circ}$ elemento começa por vogal diferente, prática em geral já adotada para os termos técnicos e científicos:

$\begin{array}{lll}\text { aeroespacial } & \text { contraindicação } & \text { protoariano } \\ \text { agroindustrial } & \text { contraofensa } & \text { pseudoalucinação } \\ \text { anteaurora } & \text { extraescolar } & \text { pseudoepígrafe } \\ \text { antiaéreo } & \text { extraoficial } & \text { retroalimentação } \\ \text { autoajuda } & \text { extrauterino } & \text { retroiluminar } \\ \text { autoaprendizagem } & \text { hidroelétrico } & \text { semiárido } \\ \text { autoestrada } & \text { infraestrutura } & \text { sobreaquecer } \\ \text { coadministrar } & \text { infraordem } & \text { supraesofágico } \\ \text { coautor } & \text { intrauterino } & \text { supraocular } \\ \text { coeducação } & \text { neoafricano } & \text { ultraelevado } \\ \text { contraescritura } & \text { neoimperialismo } & \\ \text { contraespiona } & \text { plurianual } & \end{array}$

b) Quando o $1^{\circ}$ elemento termina por vogal e o $2^{\circ}$ elemento começa por $r$ ou $s$, devendo duplicar-se essas consoantes, prática já generalizada em palavras desse tipo pertencentes aos domínios científico e técnico.

$\begin{array}{lll}\text { antessala } & \text { eletrossiderúrgica } & \text { protossatélite } \\ \text { antirreligioso } & \text { extrarregular } & \text { pseudossigla } \\ \text { antissemita } & \text { infrarrenal } & \text { semirrígido } \\ \text { antissocial } & \text { infrassom } & \text { sobressaia } \\ \text { autorregulamentação } & \text { microssistema } & \text { suprarrenal } \\ \text { contrarregra } & \text { misissaia } & \text { ultrassonografia } \\ \text { contrassenha } & \text { neorrinoplastia } & \\ \text { cosseno } & \text { neorromano } & \end{array}$




\section{B) Nas formas com sufixo}

Emprega-se o hífen apenas nos vocábulos terminados pelos sufixos de origem tupi-guarani -açu, -guaçu, -mirim, quando o $1^{\circ}$ elemento termina por vogal acentuada graficamente, ou quando a pronúncia exige a distinção gráfica dos dois elementos: amoré-guaçu, anajá-mirim, andá-açu, capim-açu, Ceará-Mirim

Para concluir esta série de considerações em defesa do Acordo de 1990, vale a pena aludir a mais duas críticas muito frequentes nas entrevistas. A primeira delas atende à grande presença de acentos gráficos num sistema que se considera "simplificador". E logo a seguir, o crítico se refere, nesse particular, à excelência da ortografia inglesa, que não usa acentos. O confronto é antigo entre nós, e sempre é lembrado com a chancela de Monteiro Lobato que, no livro Emilia no pais da gramática, declara textualmente, quase no final da obra, na reclamação da dama Ortografia contra o uso excessivo dos acentos no português:

Sou contra isso: quanto menos acento houver numa língua, melhor. A língua inglesa, que é a mais rica de todas, não se utiliza de nenhum acento. Os ingleses são homens práticos. Não perdem tempo em enfeitar as palavras com bolostroquinhas dispensáveis. (p.139 da ed. de 1955)

$\mathrm{Na}$ verdade, não é por serem práticos que os ingleses não usam acentos para marcar a sílaba tônica. Não o fazem, porque no inglês, como noutras línguas (o latim clássico ou as línguas germânicas), a posição da sílaba tônica é estruturalmente determinada, fato que não ocorre no português.

A outra crítica diz respeito à pretensa inconstitucionalidade do ato do governo que impôs a obediência do novo sistema ortográfico a todos os usuários do idioma. A matéria ortográfica da língua portuguesa nunca se apresentou como de natureza plebiscitária. Sobre esse aspecto do problema, Fernando Pessoa, em lúcidas páginas que ficaram inéditas até pouco tempo, referiu-se ao fato de que a ortografia apresenta dois aspectos que precisam ser bem distinguidos. Um aspecto cultural, pelo qual a pessoa grafa as palavras de acordo com a sua cultura, ou como aprendeu nos bancos escolares. Isso dá o direito de opções variadas ao usuário, como fizeram, por exemplo, os escritores de todos os tempos. Todavia, o aspecto social da ortografia, em que o texto se destina a uma multidão de usuários, não deve oferecer espaço para essa pletora de grafias pessoais, cuja indisciplina irá dificultar a difusão do texto entre todos. Daí entra o papel do governo que, como indivíduo coletivo, tem de evitar a indisciplina. E é nesse momento que apela para a colaboração dos técnicos que se dedicam a estudos linguísticos e que, em geral, se encontram nas academias de letras e nas universidades. São essas duas instituições que fixam o aspecto social dos sistemas ortográficos. Já no prefácio da $\mathrm{l}^{\mathfrak{a}}$ ed. do poema Camões, em 1825, Almeida Garrett conclama governo e academia para a solução de uma ortografia uniformizada entre todos os usuários: 
Sobre ortografia (que é força cada um fazer a sua entre nós, porque não a temos), direi só que segui sempre a etimologia em razão composta com a pronúncia; que acentos só os pus onde sem eles a palavra se confundiria com outra; e que de boamente seguirei qualquer método mais acertado, apenas haja algum geral e racionável em português: o que tão fácil e simples seria se a nossa Academia e Governo em tão importante coisa se empenhassem.

Por tudo isso, a adoção do Acordo de 1990 seguiu o semelhante rito oficial começado na reforma de 1911: com o concurso do Governo Português e da Academia das Ciências de Lisboa.

RESUMO - O presente texto pretende comentar críticas não só às propostas do Acordo Ortográfico de 1990, mas também explicitar de forma acessível ao leitor comum a filosofia que presidiu a elaboração do texto aprovado pelas nações que têm o português como língua oficial. Pretende ainda lembrar aos críticos que o Acordo só tratou dos pontos que se mostravam divergentes entre o sistema de 1945 - vigente em Portugal e nos países africanos - e o sistema de 1943 - vigente no Brasil. As formas não discordantes não entraram na mesa de discussão: trata-se de Acordo, e não de Reforma.

PALAVRAS-CHAVE: Ortografia, Ortografia oficial, Variante linguística, Variante gráfica e aspecto cultural e social da ortografia.

ABSTRACT - This paper aims to not only review the criticism of the proposals of the 1990 Orthographic Agreement, but also to provide accessible explanation for the common reader of the philosophy that guided the drafting of the text adopted by the nations where Portuguese is the official language. It also aims to remind critics that the Agreement addressed only topics showed divergence between the 1945 system in effect in Portugal and in African countries, and the 1943 system in effect in Brazil. Forms that showed no discrepancy were not on the discussion table. The treaty was an Agreement, not a Reform.

KEYWORDS: Orthography, Official orthography, Linguistic variant, Graphic variant, Cultural and social aspect of orthograph

Evanildo Bechara é professor, gramático e filólogo. É membro correspondente da Academia das Ciências de Lisboa e doutor honoris causa pela Universidade de Coimbra. Professor titular e emérito da Universidade do Estado do Rio de Janeiro e da Universidade Federal Fluminense. É membro da Academia Brasileira de Filologia e da Academia Brasileira de Letras. Autor de várias das principais gramáticas da língua destinadas tanto ao público leigo quanto a profissionais da área: Moderna gramática portuguesa; Gramática escolar da lingua portuguesa; Lições de português pela análise sintática.@-ebechara@academia.org.br

Recebido em 22.1.2015 e aceito em 10.2.2015.

I Academia Brasileira de Filologia, Academia Brasileira de Letras, Rio de Janeiro/RJ, Brasil. 